\title{
Leitura integrada da gestão dos recursos hídricos com o uso do solo em Caraguatatuba (SP)
}

\author{
Integrated screening of the management of water \\ resources and spatial plan at Caraguatatuba (São Paulo, Brazil)
}

Francisco Fabbro Neto', Marcelo Pereira de Souza²

\begin{abstract}
RESUMO
A conservação dos recursos hídricos demanda ações de controle do uso e da ocupação do solo, influenciando instrumentos de gestão territorial nas escalas regional e local. O objetivo deste artigo foi analisar os instrumentos de planejamento territorial aplicados no Brasil, tendo como estudo de caso o litoral norte do Estado de São Paulo. A metodologia é baseada na análise da articulação dos dispositivos legais, notadamente a Política Nacional dos Recursos Hídricos, o Estatuto da Cidade, o Plano de Bacia Hidrográfica, o Zoneamento Ecológico-Econômico e o Plano Diretor Municipal. Como resultados, são apontadas dificuldades relacionadas ao uso de instrumentos normativos de integração, com a ausência de ferramentas de suporte à decisão das distintas competências.
\end{abstract}

Palavras-chave: plano de bacia hidrográfica; plano diretor municipal; zoneamento ecológico-econômico; gestão territorial.

\begin{abstract}
The conservation of water resources deals with spatial plans, influencing territorial management tools at regional and local scale. This paper aimed to analyze the planning tools applied in Brazil, focusing on the Northern Coast of São Paulo. The methodology was based on the analysis on the articulation of laws: Politica Nacional de Recursos Hidricos, Estatuto da Cidade, Plano de Bacia Hidrográfica, Zoneamento Ecológico-Econômico and Plano Diretor Municipal. As results, there are troubles in the laws interaction's, with lack of decision support tools.
\end{abstract}

Keywords: water basin management plan; local development plan; environmental zonning; land use management.

\section{INTRODUÇÃO}

O planejamento na escala regional é particularmente importante por permitir a consideração prévia de tendências e atividades que ameaçam a qualidade ambiental, como o crescimento urbano local (MASCARENHAS; RAMOS; NUNES, 2012). Segundo Helbron et al. (2011), os instrumentos de planejamento territorial regional representam compromissos entre objetivos distintos de uso e ocupação do solo em áreas específicas, com potencial para promover o desenvolvimento social e econômico articulado à proteção dos recursos hídricos.

Segundo Valenzuela Montes e Matara'n Ruiz (2008), o planejamento de uso e ocupação do solo normalmente é tratado de maneira isolada à gestão dos recursos hídricos, assim como a gestão dos recursos hídricos vem sendo feita somente por especialistas, distanciando-se de outras considerações setoriais e compromissos políticos (GRINDLAY et al., 2011).
No Brasil, o tema da gestão de recursos hídricos está, prioritariamente, relacionado aos Estados e à União, enquanto a Constituição Federal atribui ao município a competência para legislar sobre o uso e a ocupação do solo. Na busca pela articulação de competências, a Lei Federal n 12.608/12 (BRASIL, 2012), Política Nacional de Proteção e Defesa Civil, no seu art. 26, altera a Lei n ${ }^{\circ}$ 10.257/01 (BRASIL, 2001), Estatuto da Cidade, que passa a vigorar acrescida de diferentes artigos, incluindo o art. 42-A, $\$ 2^{\circ}$, que determina que o conteúdo do plano diretor deva ser compatível com as disposições presentes nos planos de recursos hídricos, formulados segundo a Lei no 9.433/97 (BRASIL, 1997), Plano Nacional de Recursos Hídricos (PNRH). Dessa maneira, o planejamento de uso e ocupação do solo é fortalecido pela consideração do sistema hidrológico. Esses dispositivos legais devem influenciar a elaboração do Plano de Bacia Hidrográfica (PBH), Zoneamento Ecológico-Econômico (ZEE) e Plano Diretor Municipal (PDM).

'Doutor em Ciências da Engenharia Ambiental, Arquiteto e Urbanista pela Escola de Engenharia de São Carlos da Universidade de São Paulo (USP) - São Carlos (SP). Professor da área de Infraestrutura do Instituto Federal de Educação, Ciência e Tecnologia de São Paulo (IFSP) - Caraguatatuba (SP), Brasil.

2Doutor em Saúde Pública pela USP - São Paulo (SP). Professor Titular do Departamento de Biologia da Faculdade de Filosofia, Ciências e Letras da USP - Ribeirão Preto (SP), Brasil. Endereço para correspondência: Francisco Fabbro Neto - Rua Rio Grande do Norte, 450 - Indaiá - 11665-310 - Caraguatatuba (SP), Brasil - E-mail: ffneto@ifsp.edu.br Recebido: 05/10/15 - Aceito: 16/09/16 - Reg. ABES: 154955 
É abordada neste artigo a articulação entre as disposições legais que orientam diferentes instrumentos de planejamento no Brasil, notadamente a Lei Federal no 9.433/97 (BRASIL, 1997) (PNRH) e o Estatuto da Cidade, Lei Federal no 10.257/01 (BRASIL, 2001). Para isso, são discutidos os diferentes instrumentos legais criados para regulamentar o controle dos recursos hídricos e o uso e a ocupação do solo, com o objetivo de avaliar a sua compatibilização, tendo como estudo de caso a análise dos instrumentos aplicados no litoral norte do Estado de São Paulo. A compatibilização é verificada por meio do escopo dos instrumentos de planejamento, etapas de elaboração e participação da sociedade.

O litoral norte apresenta atualmente a maior taxa de crescimento populacional no Estado de São Paulo. A região foi selecionada pelo predomínio de interesses preservacionistas ter promovido o estabelecimento de um projeto-piloto de controle territorial regional do Governo do Estado de São Paulo na forma de ZEE. Atualmente, esse zoneamento se encontra em período de revisão, tornando oportuna a análise.

\section{MATERIAIS E MÉTODOS}

\section{Área de estudo}

O litoral norte do Estado de São Paulo é uma unidade de gerenciamento de recursos hídricos (UGRHI), que engloba os municípios de Caraguatatuba, Ilhabela, São Sebastião e Ubatuba. Essa UGRHI é classificada como um conjunto de bacias hidrográficas destinadas à conservação dos recursos naturais, sendo que cerca de $80 \%$ do seu território é protegido como unidade de conservação de uso integral, o que restringe a disponibilidade de áreas para urbanização (IPT, 2009).

Ilustrado na Figura 1, o município de Caraguatatuba se destaca por estar enfrentando um forte processo de urbanização acelerada, resultante da instalação de grandes empreendimentos e do crescimento das atividades turísticas na região (ASMUS et al., 2012; SEIXAS et al., 2010; SÃO PAULO, 2011). Em Caraguatatuba, grande parte dos empreendimentos propostos está localizada próxima a áreas territoriais especialmente protegidas na forma de Parque Estadual da Serra do Mar (PESM). Em toda a costa existem tendências de ocupação irregular nos arredores do PESM, com alta densidade de ocupação em Caraguatatuba (PARQUE ESTADUAL DA SERRA DO MAR, 2006).

\section{Metodologia}

As etapas metodológicas deste trabalho partiram da análise da legislação abrangente sobre o tema planejamento de recursos hídricos e planejamento de uso e ocupação do solo, seguido de análise de instrumentos aplicados no Estado de São Paulo. A parte do sistema de planejamento paulista avaliado neste artigo é pautado no PBH da Unidade de Gerenciamento de Recursos Hídricos do Litoral Norte do Estado de São Paulo, com o Plano Diretor Municipal de Caraguatatuba (PDMC), que são articulados por meio do ZEE do Litoral Norte de São Paulo. Por fim, após análise dos documentos, foram realizadas entrevistas com gestores dos processos estudados, a fim de elaborar diagramas para permitir a análise comparativa.

Foram analisados na Constituição Federal do Brasil (BRASIL, 1988) os capítulos referentes ao meio ambiente, art. 225, e à política

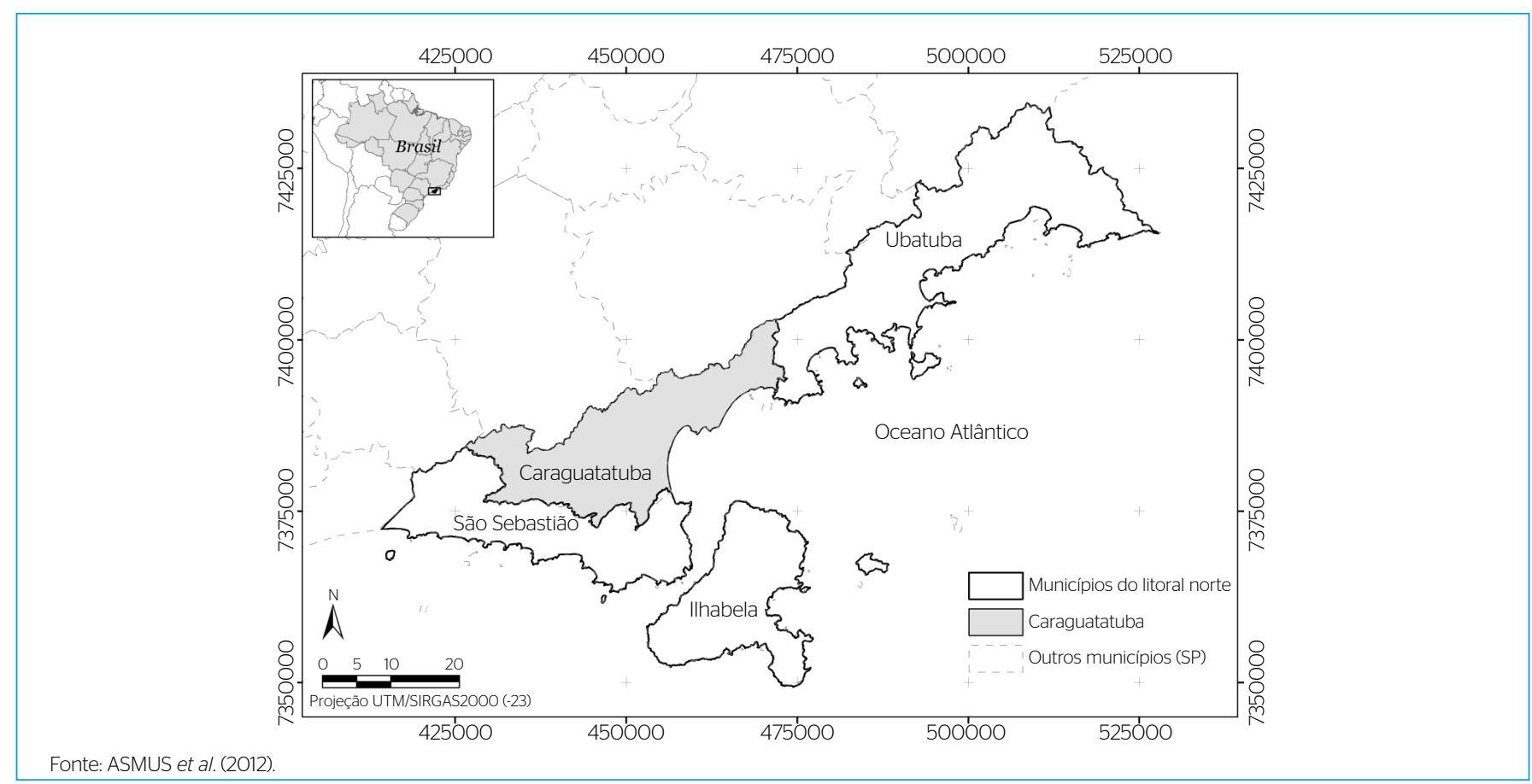

Figura 1 - Localização do município de Caraguatatuba. 
urbana, arts. 182 e 183, acompanhados dos desdobramentos legais sobre cada um desses temas nas escalas nacional, regional e municipal. Inicialmente, foi feito um estudo sobre o gerenciamento dos recursos hídricos, por meio da PNRH, Lei Federal no 9.433/97 (BRASIL, 1997), e seus desdobramentos institucionais, como a Resolução $n^{\circ}$ 05/2000 do Conselho Nacional de Gerenciamento dos Recursos Hídricos (BRASIL, 2000a), que regulamenta a criação dos comitês de bacias hidrográficas, e a Resolução no 357/05 (BRASIL, 2005) do Conselho Nacional de Meio Ambiente, que dispõe sobre o enquadramento dos corpos hídricos. As implicações dos instrumentos de gestão dos recursos hídricos foram potencializadas pelo ZEE, Decreto Federal n 4.297/02 (BRASIL, 2002).

A regulamentação exercida pelo Estado de São Paulo é verificada pelo Plano Estadual dos Recursos Hídricos de São Paulo, Lei Estadual n 9.034/94 (SÃO PAULO, 1994), a criação do Sistema de Gerenciamento de Recursos Hídricos de São Paulo, Lei Estadual no 7.663/91 (SÃO PAULO, 1991) e a regulamentação do Fundo Estadual dos Recursos Hídricos de São Paulo, Decreto Estadual n 37.300/93 (SÃO PAULO, 1993). As ações desempenhadas na escala regional são implementadas pelo Plano de Bacia Hidrográfica do Litoral Norte de São Paulo para 2009 a 2012 (PBHLN), e pelo ZEE do Litoral Norte de São Paulo, Decreto Estadual no 49.215/04 (SÃO PAULO, 2004). O processo de elaboração do PBHLN, com suas respectivas etapas e momentos de participação da sociedade, são apresentados a fim de que sejam identificadas as possíveis influências sobre a gestão territorial.

Os desdobramentos do Plano de Gerenciamento de Recursos Hídricos sobre o controle territorial são verificados a partir do ZEE do Litoral Norte do Estado de São Paulo, que por sua vez incorpora diretrizes propostas pelo Plano de Manejo do Parque Estadual da Serra do Mar. Esses instrumentos regionais de planejamento apresentam diretrizes para o detalhamento das informações e controle do uso e da ocupação do solo local a serem estipulados pelo PDM.

Foram realizadas duas reuniões com o assistente da secretaria executiva do comitê de bacia hidrográfica do litoral norte, em Ubatuba. A primeira reunião ocorreu em abril de 2011, para discutir e esclarecer o processo de planejamento de recursos hídricos e a implementação do PBHLN. A segunda reunião ocorreu em novembro de 2012, para discutir e esclarecer as relações do PBHLN com o planejamento de uso e ocupação do solo, pautado na articulação entre o ZEE do Litoral Norte e o PDM. Por fim, $\mathrm{o}$ assistente entrevistado contribuiu na formulação de um diagrama para representar as etapas e conteúdos do processo de planejamento de recursos hídricos, apresentado na seção "Plano de Bacia Hidrográfica” deste artigo.

Posteriormente as regulamentações sobre o uso e a ocupação do solo no Brasil são apresentadas. O Estatuto da Cidade, Lei Federal no 10.257/01 (BRASIL, 2001), que regulamenta a Política Urbana, é estudado tendo como perspectiva a elaboração do PDM. Os procedimentos adotados na elaboração do referido plano são apresentados junto ao conteúdo de cada etapa. Os momentos de discussão e participação da sociedade durante a tomada de decisão são identificados.
Foi realizada uma reunião, em dezembro de 2012, com a diretora-executiva da Agenda 21 local de Caraguatatuba e membro do Comitê de Bacia Hidrográfica do Litoral Norte de São Paulo (CBHLN), para discutir e esclarecer o processo de elaboração do PDMC e suas relações com os recursos hídricos. Por fim, a diretora-executiva contribuiu na elaboração um diagrama para ilustrar as etapas e conteúdos do processo de planejamento, apresentado na seção "Planejamento Municipal: Plano Diretor Municipal” deste artigo.

A articulação dos instrumentos de planejamento elaborados para o litoral norte do Estado de São Paulo é discutida frente às diferentes competências entre os níveis de governo. Similaridades nos procedimentos adotados nos diferentes instrumentos estudados são apontadas a fim de que sejam identificadas oportunidades de integração entre os instrumentos de gestão dos recursos hídricos e uso e ocupação do solo.

\section{ANÁLISE INVESTIGATIVA E CRÍTICA DAS POLÍTICAS E DOS INSTRUMENTOS DE PLANEJAMENTO}

\section{Planejamento regional: plano de bacia hidrográfica e zoneamento ecológico-econômico}

\section{Plano de bacia hidrográfica}

Em 1997, foi aprovada a Lei Federal no 9.433/97 (BRASIL, 1997), que institui a PNRH, criando o Sistema Nacional de Gerenciamento de Recursos Hídricos, que regulamenta o inciso XIX do art. 21 da Constituição Federal, substituindo o Código de Águas, de 1934, que até então era o único instrumento legal abrangente e específico sobre recursos hídricos no país (SÃO PAULO, 1997). Entre os seus fundamentos está o reconhecimento da bacia hidrográfica como unidade básica de gestão, sendo que o gerenciamento dos recursos hídricos deve possibilitar o uso múltiplo da água, com gestão descentralizada, a fim de que envolva a participação do governo, dos usuários e das comunidades locais (BRASIL, 1997).

Segundo Milaré (2004), os planos de recursos hídricos são elaborados por bacia hidrográfica, por Estado e para o país, constituindo-se em instrumento de planejamento estratégico, em um processo integrado que leva em consideração tanto as necessidades de longo prazo quanto horizontes mais curtos, incorporando considerações ambientais, econômicas e sociais. No caso do Estado de São Paulo, o gerenciamento das bacias hidrográficas considera os aspectos físicos, isto é, os divisores hidrográficos, a hidrogeologia, o clima, os solos e os aspectos ambientais (SÃO PAULO, 1997).

A Lei Estadual no 9.034/94 (SÃO PAULO, 1994) dividiu o Estado de São Paulo em 22 UGRHI. Foi estabelecida a necessidade da hierarquização dos usos prioritários da água, indicando os investimentos 
recomendados para as bacias, com base nas prioridades e metas de qualidade, e o conteúdo dos relatórios anuais de situação dos recursos hídricos.

A Lei no 7.663/91 (BRASIL, 1991) cria o Fundo Estadual de Recursos Hídricos (FEHIDRO) como instrumento de apoio financeiro da Política Estadual de Recursos Hídricos, sendo posteriormente regulamentado pelo Decreto Estadual no 37.300/93 (SÃO PAULO, 1993). Dos recursos previstos em lei, foram alocados ao FEHIDRO aqueles provenientes da compensação financeira pelo aproveitamento hidroenergético, pagos pelo governo federal. Esses recursos devem ser utilizados nas bacias hidrográficas, em projetos, serviços e obras previstos em instrumentos de planejamento (SÃO PAULO, 1997). É na instância da bacia hidrográfica que os instrumentos da PNRH serão aplicados, efetivando, assim, a gestão integrada dos recursos hídricos.

De acordo com Calasans et al. (2003), há uma interdependência sequencial para a implementação dos diferentes instrumentos da PNRH. Preferencialmente, iniciam-se pela elaboração do Plano de Recursos Hídricos, que deve conter o enquadramento dos corpos hídricos em classes, as prioridades para outorga de direito de uso e a definição de diretrizes e critérios para a cobrança.

A Resolução CONAMA n 357/2005 (BRASIL, 2005) regulamenta o enquadramento dos corpos d'água, estabelecendo a classificação de acordo com a qualidade requerida para os usos preponderantes ou usos pretendidos. Quando o padrão de qualidade não atender aos usos pretendidos, pode-se estabelecer um conjunto de metas para que se consiga alcançá-los (UMBUZEIRO \& LORENZETTI, 2009).

A outorga deve ser concedida com base nos estudos realizados sobre disponibilidade hídrica da bacia face às metas estabelecidas pelo enquadramento. Com isso, viabiliza-se a cobrança pelo uso dos recursos hídricos, como mecanismo assegurador dos usos múltiplos da água naquela bacia. A cobrança pelo uso da água deve começar, prioritariamente, a ser implementada em bacias em que o conflito pelo uso ou a degradação ambiental dos recursos hídricos já sejam problemas reais (LIMA, 2003).

A Resolução nº 05/2000 (BRASIL, 2000a), do Conselho Nacional de Gerenciamento dos Recursos Hídricos, regulamenta a criação dos comitês de bacias hidrográficas como órgãos colegiados com atribuições normativas, deliberativas e consultivas a serem exercidas nas bacias hidrográficas de sua área de atuação, destacando, como diretrizes de ação para implementação da PNRH, a adequação da gestão da água à diversidade física, biótica e socioeconômica das diversas regiões do país e a articulação do planejamento de recursos hídricos com a gestão ambiental e do uso e ocupação do solo.

Segundo Oliveira e Amarante Júnior (2009), o Plano de Recursos Hídricos é um instrumento que prevê as prioridades de ação, articulando-se com as políticas de desenvolvimento regional, constituindo-se em um estudo prévio de viabilidades, como um inventário da bacia.
O Plano de Recursos Hídricos pode estabelecer diretrizes para o uso e a ocupação do território na respectiva bacia hidrográfica, incorporando conceitualmente o controle e o monitoramento do impacto da ocupação territorial na oferta de água em quantidade suficiente e qualidade aceitável. Esses planos, em longo prazo, contemplam a análise de alternativas de crescimento demográfico, de evolução de atividades produtivas e de modificações dos padrões de ocupação do solo, com apresentação de propostas para a criação de áreas sujeitas à restrição de uso, com vistas à proteção dos recursos hídricos.

No Estado de São Paulo, o comitê de bacia hidrográfica do litoral norte é o responsável pelo PBH da Unidade de Gerenciamento de Recursos Hídricos do Litoral Norte (UGRHI 03). O processo de elaboração do referido plano é apresentado na Figura 2.

A Figura 2 descreve a sequência de procedimentos do $\mathrm{PBH}$, com os respectivos indicadores utilizados em cada etapa. $\mathrm{O} \mathrm{PBH}$ inicia com os objetivos da PNRH e todas as futuras etapas devem segui-lo. Primeiramente, cada corpo hídrico é identificado e classificado entre superficial, costeiro ou subterrâneo. A partir da identificação de cada corpo hídrico é possível o estabelecimento de seu uso proposto e consequente enquadramento em classes estabelecidas pela Resolução CONAMA nº 357/05 (BRASIL, 2005). Segundo Pizella e Souza (2007), a definição da classe de qualidade do corpo hídrico é atributo do comitê de bacia hidrográfica, que deve exercê-lo mediante audiências públicas, com o intuito de conhecer as demandas envolvidas. No entanto, todos os corpos hídricos da UGRHI 3 foram enquadrados nas classes 1 e 2 pelo Decreto Estadual no 10.755/77 (SÃO PAULO, 1977), o que representa a demanda, pelo menos, de suficiente qualidade da água para consumo humano após tratamento convencional, proteção das comunidades aquáticas, recreação de contato primário, irrigação de hortaliças e plantas frutíferas, aquicultura e atividades de pesca.

A próxima etapa é o diagnóstico dos aspectos físico-químicos (materiais flutuantes, óleos e graxas, propriedades organolépticas, $\mathrm{pH}$, fósforo, clorofila, fenóis, etc.) e biológicos (coliformes termotolerantes, densidade de cianobactérias, etc.) de cada corpo hídrico. As condições atuais do corpo hídrico comparados com os padrões de qualidade requeridos para o uso proposto permitem identificar as pressões a serem gerenciadas para o atendimento da demanda.

As pressões ambientais na bacia são exercidas por demandas de captação (abastecimento doméstico, uso industrial, irrigação) outorgadas pelo Departamento de Águas e Energia Elétrica (DAEE), ou por poluição (despejo de efluentes, atividades agrícolas, disposição de resíduos sólidos, atividades mineradoras e processos erosivos).

Como na UGRHI 03, os aspectos qualitativos dos recursos hídricos estão aquém do necessário de maneira generalizada, os deficit de saneamento ambiental e a incidência de doenças de veiculação hídrica foram utilizados a fim de selecionar uma sub-bacia para intervenção prioritária (IPT, 2009). O Relatório de Situação de Recursos Hídricos também subsidiam a seleção da sub-bacia prioritária, sendo que esse relatório é 
formulado pelo Governo do Estado de São Paulo, composto por 64 indicadores selecionados entre dados oficiais do DAEE, Companhia de Saneamento Básico do Estado de São Paulo (SABESP) e Companhia de Tecnologia de Saneamento Ambiental de São Paulo (CETESB).

Após tal seleção, são estabelecidos os mecanismos de ação, definidos na forma de financiamento de ações, detalhamento de estudos e ações de capacitação, mobilização e articulação da sociedade. Os respectivos responsáveis por cada mecanismo são indicados entre os diferentes níveis de governo.

As propostas de ações são avaliadas por meio de oficinas participativas com membros de câmaras técnicas e grupos de trabalho do comitê de bacia hidrográfica, técnicos de planejamento da Secretaria Estadual de Meio Ambiente e outros interessados (IPT, 2009). As Câmaras Técnicas podem possuir composição tripartite, formadas pela sociedade civil, órgãos públicos e setores econômicos, com a função de assessorar o plenário do Comitê de Bacia Hidrográfica $(\mathrm{CBH})$ na tomada de decisão sobre os assuntos que lhe são submetidos. São consultivas, mas não deliberativas. Os problemas que surgem nas bacias devem determinar a criação das câmaras que podem ser permanentes ou temporárias (SÃO PAULO, 1997).

Finalmente, as metas e os prazos para as ações previstas constituem o Plano de Recuperação e Conservação, acompanhado do Plano de Investimentos do Poder Público, que será subsidiado pelo FEHIDRO. O PBH é apresentado e deve ser apreciado pelo colegiado deliberativo do comitê de bacia hidrográfica, necessariamente de composição tripartite.
O monitoramento da eficácia e da implementação das ações previstas no PBH é feito durante a atualização do Relatório de Situação de Recursos Hídricos, o qual avalia o cumprimento dos programas previstos para a UGRHI 03 (INSTITUTO PÓLIS, 2013).

O PBHLN para o período de 2009 a 2012 estipula que as ações referentes ao saneamento básico e à educação ambiental são prioritárias para toda a UGRHI 03 (IPT, 2009).

\section{Zoneamento ecológico-econômico}

Para dar suporte ao estabelecimento de vedações, restrições e alternativas de exploração do território, com o fortalecimento de medidas e padrões de qualidade ambiental e dos recursos hídricos, foi criado o Decreto Federal $\mathrm{n}^{\circ} 4.297 / 2002$ (BRASIL, 2002), ZEE. Trata-se de um instrumento normativo, responsável por organizar, de forma vinculada, as decisões dos agentes públicos e privados, quanto a planos, programas, projetos e atividades que, direta ou indiretamente, utilizem recursos naturais.

No âmbito do Estado de São Paulo, o Decreto no 49.215/04 (BRASIL, 2004) dispôs sobre o zoneamento do litoral norte, considerando a necessidade de promover o ordenamento territorial e de disciplinar os usos e atividades de acordo com a capacidade de suporte do ambiente, constituindo um marco no processo de implantação do gerenciamento territorial regional calcado na articulação ZEE e Plano de Recursos Hídricos (SÃO PAULO, 2005).

O ZEE do litoral norte abrange toda a área da UGRHI 03, exceto a área pertencente ao PESM. Por se tratar de uma unidade de conservação

Lei Federal no 9.433/97 - Plano Nacional de Recursos Hídricos - Uso múltiplo das águas

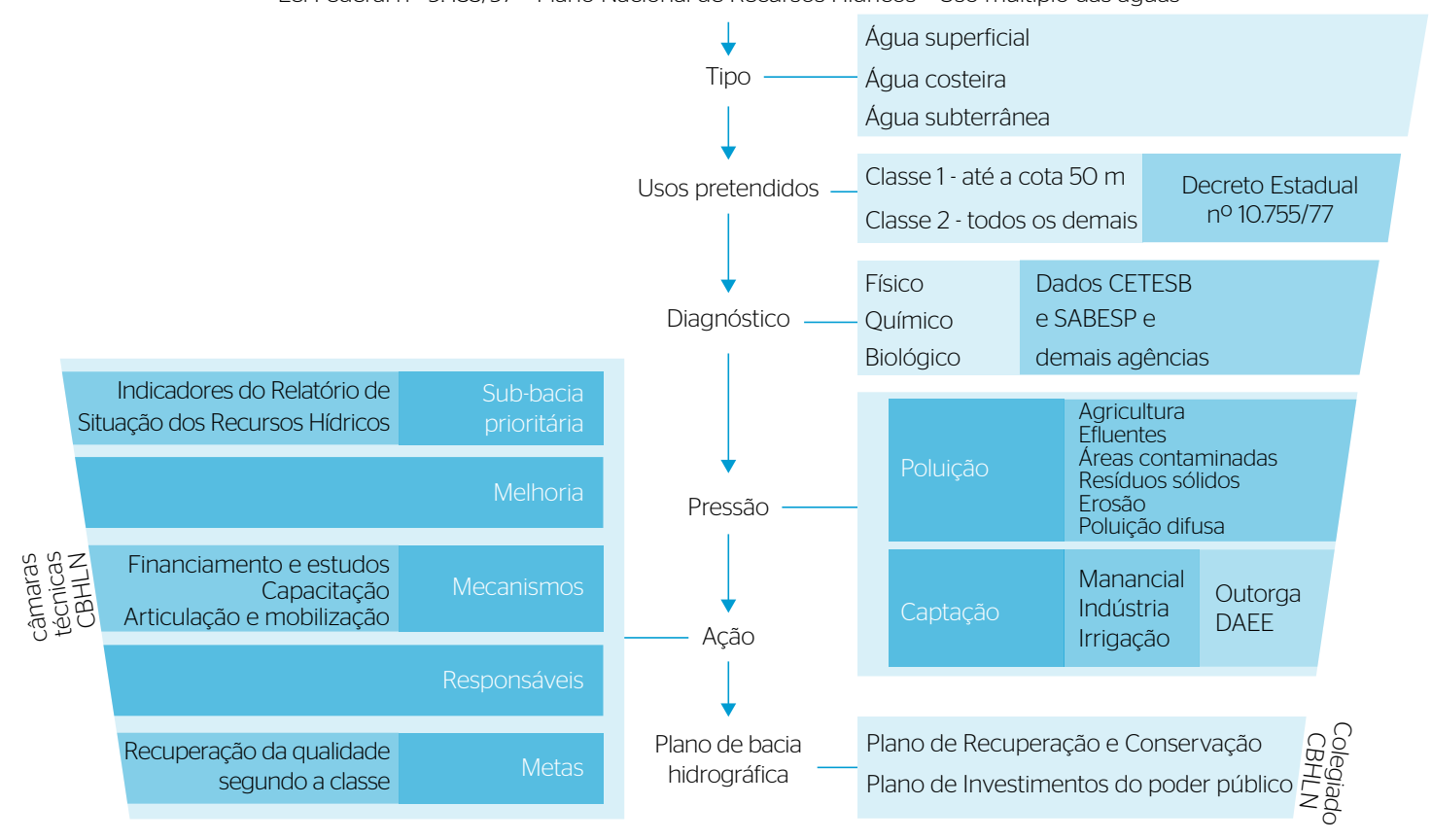

CETESB: Companhia de Tecnologia de Saneamento Ambiental de São Paulo; SABESP: Companhia de Saneamento Básico do Estado de São Paulo; DAEE: Departamento de Águas e Energia Elétrica; CBHLN: Comitê de Bacia Hidrográfica do Litoral Norte de São Paulo.

Figura 2 - Etapas e procedimentos do Plano de Bacia Hidrográfica do Litoral Norte. 
estabelecida nos moldes da Lei no 9.985/00 (BRASIL, 2000b), o PESM possui um plano de manejo próprio com respectiva zona de amortecimento, área que ocupa uma faixa de dez quilômetros ao redor do limite do PESM, onde é passível de serem estipuladas diretivas de ocupação mais restritivas visando à proteção do parque.

Uma parcela do município de Caraguatatuba lindeira ao PESM foi classificada como Zona 3 Terrestre (Z3T) pelo ZEE do litoral norte de São Paulo, por possuir ocupação humana com características rurais, silvicultura e unidades de beneficiamento agropecuárias. A meta mínima de conservação ou recuperação prevê $50 \%$ dessa zona com cobertura vegetal nativa, por meio da formação de corredores ecológicos entre remanescentes de vegetação (SÃO PAULO, 2004). De acordo com o ZEE do litoral norte, os usos permitidos para a Z3T são atividades agropecuárias, compreendendo unidades integradas de beneficiamento, processamento ou comercialização dos produtos agroflorestais e pesqueiros, desde que compatíveis com as características ambientais da zona; atividades de silvicultura; e ocupação humana com características rurais (SÃO PAULO, 2004). De acordo com os aspectos geotécnicos do município de Caraguatatuba e região, é possível verificar que a área classificada como Z3T pelo ZEE do litoral norte apresenta alta suscetibilidade a inundações, recalques, assoreamento e solapamento das margens dos rios (ARCADIS TETRAPLAN, 2010).

De acordo com Helbron et al. (2011), medidas de controle de uso e ocupação do solo previstas durante o planejamento regional se concentram, principalmente, em especificação de zonas com objetivos específicos, o que resulta em importante instrumento de apoio e diretrizes para outros níveis de governo. A escala de detalhamento das informações espaciais é fundamental para garantir a eficácia das medidas propostas (JOÃO, 2002; GONZÁLEZ et al., 2011).

O poder público municipal é responsável pelo detalhamento das diretrizes estipuladas em âmbito regional pelo $\mathrm{PBH}$ do litoral norte e ZEE do litoral norte, assim como a incorporação das diretrizes de ocupação da zona de amortecimento determinadas no Plano de Manejo do PESM. No litoral norte do Estado de São Paulo, o PDM deveria ser elaborado a partir das orientações existentes no $\mathrm{PBH}$ do litoral norte, ZEE do litoral norte e Plano de Manejo do PESM, configurando um processo sequenciado das decisões articuladas com outros níveis de governo.

\section{Planejamento municipal: plano diretor municipal}

Segundo Silva (2006), o Estatuto da Cidade, instituído pela Lei no 10.257 , de 2001 (BRASIL, 2001), estabelece diretrizes gerais da política urbana ao regulamentar os artigos 182 e 183 da Constituição Federal. O Estatuto da Cidade define o PDM como instrumento básico da política de uso e ocupação do solo municipal, devendo estabelecer os objetivos buscados, o prazo em que devem ser alcançados, as atividades a serem executadas e quem deve executá-las.

Segundo Mukai (2002), no Brasil, o PDM é o instrumento técnico-legal definidor dos objetivos de cada municipalidade, mesmo com supremacia sobre os outros para orientar toda atividade da administração e dos administrados nas realizações públicas e particulares que interessem ou afetem a comunidade. Na fixação dos objetivos e na orientação do desenvolvimento do município, é a lei suprema e geral que estabelece as prioridades nas realizações do governo local, conduz e ordena o crescimento da cidade, disciplina e controla as atividades urbanísticas em benefício do bem-estar social.

Por expressa disposição legal, disciplinada no art. $40, \S 4^{\circ}$, inciso I do Estatuto da Cidade, a participação popular e de associações representativas da comunidade está prevista por meio das audiências públicas, no processo de aprovação do PDM e no momento de sua fiscalização.

Atualmente, para que um processo de planejamento permanente seja considerado adequado à realidade do município, é necessária a observância de alguns princípios básicos, como a complementaridade e integração de políticas, planos e programas setoriais, respeito e adequação à realidade regional e local, consonância com os planos e programas estaduais e federais existentes e possibilidade de democratização e acesso às informações disponíveis (SILVA, 2006).

A prefeitura é a responsável pela elaboração do PDM, que deve ser aprovado e transformado em lei pela câmara municipal. O processo de elaboração do referido plano é apresentado na Figura 3.

A Figura 3 descreve a sequência de procedimentos para o PDM. O PDM inicia com as orientações do Estatuto da Cidade, isto é, o estabelecimento e cumprimento da função social da propriedade, e todas as etapas do PDM devem atender ao Estatuto da Cidade.

Primeiro é realizado o diagnóstico atual, contemplando aspectos relativos à infraestrutura existente, oferta de serviços urbanos e recursos naturais. É realizado um levantamento da oferta e demanda de infraestrutura para que sejam identificadas as condições de distribuição dos ônus e benefícios dos serviços municipais. As disparidades identificadas são utilizadas para o estabelecimento de ações prioritárias para a correção dos problemas sociais.

Lei Federal no 10.257/01 -

Estatuto da Cidade - Equidade socia

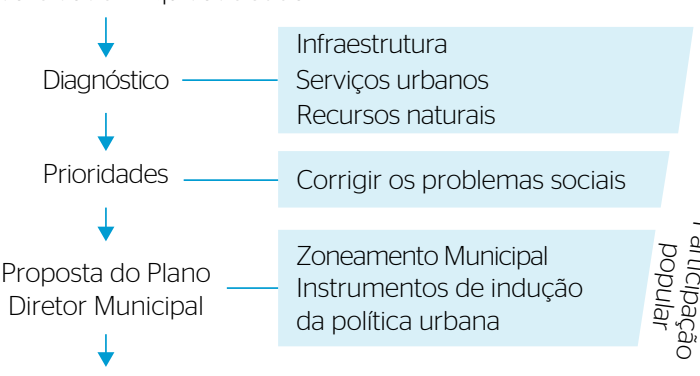

Aprovação do poder legislativo municipal

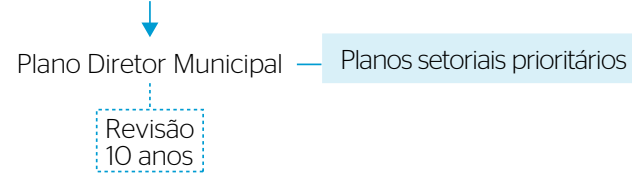

Figura 3 - Etapas e procedimentos do Plano Diretor Municipal. 
A partir do reconhecimento da situação atual do desenvolvimento municipal, é criado um zoneamento municipal para diferenciar as áreas da cidade passíveis de controle por meio dos instrumentos de indução da política urbana. Segundo Geneletti (2012), os planos de uso e ocupação do solo local preveem o estabelecimento de regras para o zoneamento espacial, com restrições e incentivos para viabilizar o gerenciamento ambiental. A proposta é apresentada na forma de um projeto de lei, que deve ser discutido em audiências públicas com a população.

Depois de estabelecidos e realizados os ajustes necessários, o projeto de lei é encaminhado para análise para o poder legislativo municipal. Uma vez aprovado, é transformado em Lei Orgânica Municipal na forma de Plano Diretor, que deve ser revisto a cada dez anos.

O PDM limita seu conteúdo ao âmbito estratégico de decisão, podendo conter o indicativo dos planos setoriais complementares a serem realizados em função das prioridades estipuladas pelo poder público municipal, como por exemplo, as questões relativas aos recursos hídricos.

\section{RESULTADOS E DISCUSSÃO}

Os processos de elaboração do PBHLN e o PDM são realizados isoladamente, em escalas e competências distintas. Em tais processos é prevista somente a participação da sociedade nas etapas finais de aprovação, o que pode ser muito tarde para ser efetiva. O escopo de cada instrumento analisado não facilita a compatibilização de interesses dos recursos hídricos ao uso e ocupação do solo. O PBHLN limita sua área de atuação sobre os recursos hídricos em si, não gerenciando as demais atividades que possam impactar a disponibilidade e qualidade da bacia hidrográfica, o que diminui a interação direta das ações de planejamento com outros setores. O escopo restrito aos recursos hídricos, somado à carência de informações sobre as atividades antrópicas exercidas na bacia hidrográfica, dificulta a identificação precisa sobre os responsáveis pela degradação ambiental, dificultando a atribuição de responsabilidades entre os atores envolvidos e, consequentemente, o financiamento das ações previstas são concentradas pelo poder público.

Já o PDM aborda as atividades de uso e ocupação do solo, postergando a discussão dos recursos hídricos na forma de planos setoriais. Para Fischer e Gazzola (2006), a separação de competências dificulta a cooperação entre diferentes níveis de governo. O planejamento local limitado à área urbana ou pautado nas interações entre o ambiente natural e construído refletem de maneira significativa na integração entre a gestão do uso e ocupação do solo com os recursos hídricos. No caso do Plano Diretor de Caraguatatuba, está prevista a expansão de áreas urbanas em desacordo com o ZEE do Litoral Norte,

A mesma parcela do município de Caraguatatuba classificada como Z3T pelo ZEE do Litoral Norte de São Paulo é classificada como Zona de Expansão Urbana pelo PDMC, após a hipotética alteração do ZEE. No PDMC, em tal zona estão previstas áreas para zona de uso logístico e retroportuário, destinado a equipamentos de grande porte; zona de suporte urbano para equipamentos de infraestrutura, como garagens e estruturas náuticas, estação de tratamento de efluentes e aterro sanitário; zona de uso industrial estratégico correlato às atividades de petróleo e gás e processamento de resíduos; zona de uso residencial, comercial e de serviços, polo tecnológico e área logística e intermodal (CARAGUATATUBA, 2011).

As diferentes características entre os usos permitidos pelo ZEE do litoral norte e os usos propostos pelo zoneamento municipal do PDMC permitem inferir que, para a definição das diretrizes de controle do território, o ZEE do litoral norte considera o diagnóstico da situação atual da área aliado aos aspectos geotécnicos da região. Por sua vez, o zoneamento municipal proposto pelo PDMC prioriza as propostas de desenvolvimento das atividades produtivas previstas para o litoral paulista.

Segundo Carter, Kreutzwiser e Lo (2005), o gerenciamento ambiental integrado é uma maneira prática de minimizar os conflitos em direção ao uso eficiente e efetivo dos recursos hídricos aliados à ocupação do solo, aproximando-se dos objetivos do desenvolvimento sustentável. De acordo com Mascarenhas, Ramos e Nunes (2012), as principais contribuições do planejamento regional estão no estabelecimento de diretrizes para o planejamento local e a promoção da coordenação e integração entre setores de desenvolvimento com políticas ambientais. No entanto, segundo Pacione (2013), as decisões vistas como socialmente aceitáveis e sustentáveis na escala regional podem ter percepções opostas na escala local.

O fortalecimento da participação da sociedade nos processos de planejamentos regional e local pode contribuir para o equilíbrio das decisões ambientais. A participação da sociedade foi formalmente reconhecida no gerenciamento de recursos hídricos e do uso e ocupação do solo no Brasil por meio de dispositivos legais previstos na Política Estadual de Recursos Hídricos, Lei Estadual n 7.663/91 (SÃO PAULO, 1991), na Política Nacional de Recursos Hídricos, Lei Federal n 9.433/97 (BRASIL, 1997) e no Estatuto da Cidade, Lei Federal no 10.257/01 (BRASIL, 2001).

O Estado de São Paulo, ao promulgar a Lei Estadual no 7.663/91 (SÃO PAULO, 1991), no art. 24, prevê a composição dos comitês de bacia hidrográfica com participação paritária entre representantes das secretarias estaduais e poder executivo municipal, sendo até um terço do número total de votos destinados aos representantes dos usuários e da sociedade civil. Já a PNRH, Lei Federal no 9.433/97 (BRASIL, 1997), no art. 39, aumenta a possibilidade de participação da sociedade civil ao estipular que, no máximo, a metade total dos membros dos comitês de bacias hidrográficas seja formada por representantes dos poderes executivos dos estados e municípios.

Dessa maneira, segundo o art. 24 da Constituição Federal de 1988 (BRASIL, 1988), que trata da legislação concorrente entre União, Estados e Distrito Federal, no seu $\$ 4^{\circ}$, é previsto que a superveniência da lei federal suspende a eficácia da lei estadual no que lhe for contrário. Sendo assim, caberia ao Estado de São Paulo regulamentar a Política Estadual de Recursos Hídricos para se adequar à PNRH, no que se refere à paridade da sociedade civil nos comitês de bacia hidrográfica. 
Tal regulamentação evitaria que a participação da sociedade seja enfraquecida pela prática paulista da política estadual de recursos hídricos.

Quanto ao gerenciamento do uso e ocupação do solo, o Estatuto da Cidade, instituído pela Lei Federal no 10.257/01 (BRASIL, 2001), art. $40, \S 4^{\circ}$, inciso I, a participação popular e de associações representativas da comunidade estão previstas por meio das audiências públicas, no processo de aprovação do PDM e no momento de sua fiscalização. Entretanto, na elaboração do PDMC, a participação da sociedade foi realizada somente após sanções judiciais aplicadas pelo ministério público federal, que suspendeu o processo em andamento e exigiu a realização de audiências públicas para sua aprovação (INSTITUTO PÓLIS, 2013).

No modelo paulista de planejamento de uso e ocupação do solo local, os resultados do sistema de planejamento municipal de Caraguatatuba reflete a participação pontual da sociedade e dos distintos setores envolvidos. A discussão entre os atores afetados somente após a elaboração do plano permite que, muitas vezes, questões importantes sejam negligenciadas. Nesse modelo de consulta à sociedade, os atores afetados são utilizados apenas como fontes de opinião, não sendo envolvidos nas estratégias de implementação e práticas de gerenciamento (CARTER; KREUTZWISER; LO, 2005). O surgimento de possíveis conflitos de interesses podem dificultar a aprovação do plano, ou mesmo requerer a revisão de todo o processo, dificultando sua continuidade e comprometendo sua eficácia.

Como regras procedimentais, existem ainda as referentes ao princípio da publicidade com a garantia à divulgação dos documentos produzidos, e acesso de qualquer interessado a tais documentos. Segundo o Estatuto da Cidade (BRASIL, 2001), art. 52, inciso VI, o chefe do poder executivo municipal incorreria em improbidade administrativa caso instituísse o PDM em desacordo com o disposto no $\$ 4^{\circ}$ do art. 40, ou seja, ao atendimento da participação popular, à publicidade dos documentos e informações produzidas e ao acesso de qualquer interessado aos documentos e informações.

Muitos participantes acreditam que o processo de participação popular oferece oportunidades iguais a todos os atores envolvidos. Contudo, os grupos mais organizados dispõem de melhores condições de negociação (BLACKSTOCK et al., 2012). Como resultado, surge o risco de dominação dos interesses dos grupos mais fortalecidos, legitimando o interesse particular como democrático (CARTER \& WHITE, 2012). Os atores sociais, com a possibilidade de exercer influência e alguns setores mais estruturados e bem organizados, podem antecipar-se a fim de conduzir o processo segundo seus objetivos, de forma desigual. Mesmo que conflitos e disputas não sejam exclusivos da sociedade civil, isso se torna mais evidente nesse segmento, pela própria heterogeneidade de sua composição, envolvendo ambientalistas, empresários, agricultores e sindicalistas (VILLAÇA, 2005).

Segundo Paoli (2002), os dispositivos de participação popular voltados às formas democráticas de discussão e deliberação podem ser eles próprios constituídos previamente por desenhos técnicos que delimitem a espontaneidade do debate e previnam transbordamentos indesejáveis.
Para Villaça (2005), os espaços de discussão, tradicionalmente no Brasil, quando criados são utilizados por aqueles atores que já possuem estrutura de participação, geralmente os grupos melhor organizados e financeiramente mais fortalecidos. No caso estudado, as divergências entre manter a Z3T como área rural ou permitir a expansão urbana em Caraguatatuba refletem a falta de integração entre a gestão dos recursos hídricos e o uso e a ocupação do solo. Esse conflito de interesses poderia ser ponderado por meio de uma avaliação de impacto ambiental. A avaliação ambiental estratégica (AAE) é instrumento desenvolvido para inserir a variável ambiental no processo de decisão de políticas, planos e programas, regulamentados pela Diretiva Europeia $n^{\circ}$ 42/2001 (GRINDLAY et al., 2011).

Segundo Gauthier, Simard e Waaub (2011), durante a aplicação da AAE é dada atenção para os procedimentos de participação da sociedade já nas etapas de definição do escopo dos estudos e da ponderação de valores dos impactos previstos. Para Jiricka e Probstil (2008), um escopo adequado identifica tópicos problemáticos no início do processo de planejamento, com o potencial de minimizar conflitos futuros, passíveis de serem avaliados de maneira holística. Os resultados dos procedimentos de consulta deveriam ser considerados durante a elaboração dos diferentes planos, incluindo a indicação de como as contribuições foram incorporadas e modificaram os resultados da decisão (STOEGLEHNER \& WEGERER, 2006).

\section{CONCLUSÃO}

No Estado de São Paulo, atualmente, a fragmentação das tomadas de decisões e processos de planejamento dificulta a implementação das ações previstas nos planos de bacia hidrográfica e PDMs. Para além de dispositivos legais já previstos, o processo de elaboração dos distintos instrumentos de planejamento deve ser integrado, incorporando a consideração das consequências ambientais e sinergia das ações propostas por outras agências setoriais, a fim de que as metas e resultados dos planos em questão convirjam para o mesmo resultado.

A aplicação da AAE poderia ser uma prática institucionalizada para auxiliar a integração da gestão dos recursos hídricos com o uso e ocupação do solo. Sendo assim, a aplicação da AAE seria conveniente já durante a elaboração/revisão do PBH e do PDM.

No caso estudado, em função das divergências entre o PBH e o PDM, está sendo proposta a alteração do ZEE. Dessa maneira, a realização de uma AAE poderia ser conduzida pelos responsáveis pela elaboração/ alteração do ZEE, isto é, a Coordenadoria de Planejamento e Educação Ambiental da Secretaria de Estado do Meio Ambiente de São Paulo. A realização da AAE poderia incluir, durante as etapas de participação da sociedade, os responsáveis pela elaboração do PBHLN e do PDMC, ou seja, representantes do comitê de bacias hidrográficas do litoral norte e da prefeitura municipal de Caraguatatuba, respectivamente.

A desarticulação institucional entre o poder público dificulta a plena implementação dos planos elaborados nas escalas regional e local, 
com consequências negativas para a efetividade dos instrumentos de planejamento. A existência de momentos de consulta interinstitucional durante a elaboração do escopo dos instrumentos de planejamento estudados neste artigo poderia contribuir para ajustar os interesses dos distintos setores durante a elaboração dos planos, tendo como resultado o aprimoramento da eficácia dos instrumentos de gestão territorial.

\section{REFERÊNCIAS}

ARCADIS TETRAPLAN (2010). Avaliação ambiental estratégica: dimensão portuária, industrial, naval e offshore no litoral paulista. São Paulo. (Relatório Técnico).

ASMUS, G.F; MELLO, A. Y. I. DE; SEIXAS, S. R. C.; BATISTELLA, M. (2O12) Análise sociodemográfica da distribuição espacial de ocorrências de diarreias agudas em áreas de risco de inundação, Caraguatatuba-SP. In: Encontro Nacional da Anppas, 6., Belém. Anais... Fortaleza: ANPPAS.

BLACKSTOCK, K.L.; WAYLEN, K.A.; DUNGLINSON, J.; MARSHALL, K.M. (2012) Linking process to outcomes: internal and external criteria for a stakeholder involvement in river basin management planning. Ecological Economics, Amsterdã, v. 77, p. 113-122.

BRASIL. Constituição. (1988). Constituição da República Federativa do Brasil. Diário Oficial da União, Brasília, DF, 05 out. 1988, v. 191-A, Seção 1, p. 1 a 32.

BRASIL. (1997). Lei no 9.433, de 8 de janeiro de 1977. Institui a política nacional de recursos hídricos, cria o sistema nacional de gerenciamento de recursos hídricos, regulamenta o inciso XIX do art. 21 da Constituição Federal, e altera o art. $1^{\circ}$ da Lei no 8.001, de 13 de março de 1990, que modificou a Lei no 7.990, de 28 de dezembro de 1989. Diário Oficial da União, Brasília, DF, 9 jan. 11 abr. 1997.

BRASIL. (2000a) Resolução no 5, de 10 de abril de 2000. Estabelece diretrizes para formação e funcionamento dos Comitês de Bacia Hidrográfica. Diário Oficial da União, Brasília, DF, 11 abr. 2000.

BRASIL. (2000b) Lei no 9.985, de 18 de julho de 2000. Regulamenta o artigo 225, parágrafo 10, incisos I, II, III e IV da Constituição Federal, institui o Sistema Nacional de Unidades de Conservação e dá outras providências. Diário Oficial da União, Brasília, DF, 19 jul. 2000. Seção I, p. 1.

BRASIL. (2001) Lei no 10.257, de 10 de julho de 2001. Regulamenta os arts. 182 e 183 da Constituição Federal, estabelece diretrizes gerais da política urbana e dá outras providências. Diário Oficial da União, Brasília, DF, 11 jul. 2001, seção I, p. 1.

BRASIL. (2002) Decreto no 4.297, de10 de julho de 2002. Regulamenta o art. 9o, inciso II, da lei no 6938, de 31 de agosto de 1981, estabelecendo critérios para o zoneamento ecológicoeconômico do Brasil - ZEE, e dá outras providências. Diário Oficial da União, Brasília, DF, 11 jul. 2002, v.132, seção I, p. 6 a 7.

BRASIL. (2005) Resolução n 357, de 17 de março de 2005. Dispõe sobre a classificação dos corpos de água e diretrizes ambientais para o seu enquadramento, bem como estabelece as condições e padrões de lançamento de efluentes, e dá outras providências. Diário Oficial da União, Brasília, DF, 18 mar. 2005, v. 53, p. 58 a 63.

BRASIL. (2012) Lei no 12.608, de 10 de abril de 2012. Institui a política nacional de proteção e defesa civil - PNPDEC; dispõe sobre o sistema nacional de proteção e defesa civil - SINPDEC e o Conselho Nacional de Proteção e Defesa Civil - CONPDEC; autoriza a criação de sistema de informações e monitoramento de desastres; altera as Leis $n^{\text {os }} 12.340$, de 10 de dezembro de 2010, 10.257, de 10 de julho de 2001, 6.766, de 19 de dezembro de 1979, 8.239, de 4 de outubro de 1991, e 9.394, de 20 de dezembro de 1996; e dá outras providências. Diário Oficial da União, Brasília, DF, 11 abr. 2012, v. 70, seção I, p. 1 a 4.

CALASANS, J.T.; REIS, D.E.C.C.; RIZZO, H.G.; TEIXEIRA, H.R.; MOREIRA, M.M.M.A. (2003) A Política Nacional de Recursos Hídricos: uma avaliação crítica. In: Congresso Internacional de Direito Ambiental, 7., São Paulo. Anais... São Paulo: Imprensa Oficial.

CARAGUATATUBA. Prefeitura da Estância Balneária de Caraguatatuba. (2011) Lei Complementar n.0 42, de 24 de novembro de 2011. Dispõe sobre o plano diretor do município da Estância Balneária de Caraguatatuba e dá outras providências. Caraguatatuba.

CARTER, J. \& WHITE, I. (2O12) Environmental planning and management in an age of uncertainty: the case of the water framework directive. Journal of Environmental Management, Amsterdã, v. 113, p. 228-236.

CARTER, N.; KREUTZWISER, R.D.; LO, R.C. (2005) Closing the circle: linking land use planning and water management at the local level. Land Use Policy, Amsterdã, v. 22, n. 2, p. 115-127.

FISCHER, T.B. \& GAZZOLA, P. (2006) SEA Effectiveness criteria equally valid in all countries? The case of Italy. Environmental Impact Assessment Review, Amsterdã, v. 26, n. 4, p. 396-409.

GAUTHIER, M.; SIMARD, L.; WAAUB, J. (2011) Public participation in strategic environmental assessment: critical review and the Quebec (Canada) approach. Environmental Impact Assessment Review, Amsterdã, v. 31, n. 1, p. 48-60.

GENELETTI, D. (2012) Environmental assessment of spatial plan policies through land use scenarios: a study in a fast-developing town in rural Mozambique. Environmental Impact Assessment Review, Amsterdã, v. 32, n. 1, p. 1-10.

GONZÁLEZ, A.; GILMER, A.; FOLEY, R.; SWEENEY, J. (2O11) Applying geographic information systems to support strategic environmental assessment: opportunities and limitations in the context of Irish land-use plans. Environmental Impact Assessment Review, Amsterdã, v. 31, n. 3, p. 368-381. 
GRINDLAY, A.L:; ZAMORANO, M.; RODRÍGUEZ, M.I.; MOLERO, E; URREA, M.A. (2011) Implementation of the European water framework directive: integration of hydrological and regional planning at the Segura River Basin, southeast Spain. Land Use Policy, Amsterdã, v. 28, n. 1, p. 242-256.

HELBRON, H.; SCHMIDT, M.; GLASSON, J.; DOWNES, N.K. (2011). Indicators for strategic environmental assessment in regional land use planning to assess conflicts with adaptation to global climate change. Ecological Indicators, Amsterdã, v. 11, n. 1, p. 90-95.

INSTITUTO DE PESQUISAS TECNOLÓGICAS - IPT. (2009) Plano de bacias hidrográficas do litoral norte 2009. Ubatuba: CETESB.

INSTITUTO PÓLIS (2013). Diagnóstico urbano socioambiental. Relatório 3: Município de Caraguatatuba. São Paulo: Litoral Sustentável.

JIRICKA, A. \& PROBSTIL, U. (2008) SEA in local land use planning first experience in the Alpine States. Environmental Impact Assessment Review, Amsterdã, v. 28, n. 4/5, p. 328-337.

JOÃO, E. (2002) How scale affects environmental impact assessment. Environmental Impact Assessment Review, Amsterdã, v. 22, n. 4, p. 289-310.

LIMA, A. (2003) O zoneamento ecológico-econômico e os comitês de bacias hidrográficas: a gestão ambiental em evolução. In: Congresso Internacional de Direito Ambiental, 7., São Paulo. Anais... São Paulo: Imprensa Oficial.

MASCARENHAS, A.; RAMOS, T.B.; NUNES, L. (2012) Developing an integrated approach for the strategic monitoring of regional spatial plans. Land Use Policy, Amsterdã, v. 29, n. 3, p. 641-651.

MILARÉ, E. (2004). Direito do ambiente: doutrina, jurisprudência, glossário. São Paulo: Revista dos Tribunais.

\section{MUKAI, T.(2002) Direito urbano-ambiental brasileiro. São Paulo: Dialética.}

OLIVEIRA, C. \& AMARANTE JÚNIOR, O. (2009) Direito internacional das águas doces. São Carlos: RiMa.

PACIONE, M. (2013) Private profit, public interest and land use planning: a conflict interpretation of residential development pressure in Glasgow's rural-urban fringe. Land Use Policy, Amsterdã, v. 32, p. 61-77.

PAOLI, M.C. (2002) - O mundo do indistinto: sobre gestão, violência e política. in: RIZEK, C.S. \& OLIVEIRA, F. (orgs.) A era da indeterminação. São Paulo: FAPESP. (Relatório parcial do subprojeto 8 da pesquisa Cidadania e Democracia: O Pensamento nas Rupturas da Política)

PARQUE ESTADUAL DA SERRA DO MAR. (2006) Plano de manejo: relatório ocupação antrópica - módulo socioeconomia e vetores de pressão. São Paulo: SMA/IF.

PIZELLA, D.G. \& SOUZA, M.P. (2007) Análise da sustentabilidade ambiental do sistema de classificação das águas doces superficiais brasileiras. Engenharia Sanitária e Ambiental, Rio de Janeiro, v. 12, n. 2, p. 139-148.

SÃO PAULO. (1977) Decreto no 10.755, de 23 de novembro de 1977. Dispõe sobre o enquadramento dos corpos receptores na classificação prevista no Decreto no 8.468, de 08 de setembro de
1976 e dá providências correlatas. Diário Oficial do Estado de São Paulo, São Paulo, Caderno Executivo, n. 221, p.1.

SÃO PAULO. (1991) Lei no 7.663, de 31 de dezembro de 1991 Estabelece normas de orientação à Política Estadual de Recursos Hídricos bem como ao Sistema Integrado de Gerenciamento de Recursos Hídricos. Diário Oficial do Estado de São Paulo, São Paulo, v. 101, n. 247, seção I, p. 2.

SÃO PAULO. (1993) Decreto no 37.300, de 26 de agosto de 1993. Regulamenta o Fundo Estadual de Recursos Hídricos - FEHIDRO, criado pela Lei no 7.663 de 30 de setembro de 1991. Diário Oficial do Estado de São Paulo, São Paulo, v. 103, n. 161, seção I, p. 2.

SÃO PAULO. (1994) Lei no 9.034, de 27 de dezembro de 1994 Dispõe sobre o Plano Estadual de Recursos Hídricos, a ser implantado no período 1994 a 1995, em conformidade com a Lei no 7.663, de 31 de dezembro de 1991, que instituiu normas de orientação à Política Estadual de Recursos Hídricos. Diário Oficial do Estado de São Paulo, São Paulo, v. 104, n. 241, seção I, p. 3.

SÃO PAULO. (1997) Secretaria do Meio Ambiente. Gestão das águas: 6 anos de percurso. São Paulo.

SÃO PAULO. (2004) Decreto n. ${ }^{\circ}$ 49.215, de 7 de dezembro de 2004. Dispõe sobre o zoneamento ecológico-econômico do setor do litoral norte, prevê usos e atividades para as diferentes zonas, estabelece diretrizes, metas ambientais e sócio-econômicas e dá outras providências, nos termos estabelecidos pela Lei n.0 10.019, de 3 de julho de 1998. Diário Oficial do Estado de São Paulo, São Paulo, v. 114, n. 230, seção I, p. 1 e 3.

SÃO PAULO. (2005). Zoneamento ecológico-econômico - litoral norte de São Paulo. São Paulo: Secretaria do Meio Ambiente.

SÃO PAULO. (2011) Secretaria do Meio Ambiente. Meio ambiente paulista: relatório de qualidade ambiental. São Paulo.

SEIXAS, S.R.C:; BARBOSA, R.V.; RENK, M.; ASMUS, G.F.; IWAMAMELLO, A.Y. (2010) Mudanças ambientais globais e saúde: uma abordagem preliminar sobre o município de Caraguatatuba, litoral norte paulista. Teoria \& Pesquisa, São Carlos, v. 19, n. 2, p. 29-59.

SILVA, J.A. (2006) Direito urbanístico brasileiro. 4. ed. São Paulo: Malheiros.

STOEGLEHNER, G. \& WEGERER, G. (2006) The SEA-directive and the SEA-protocol adopted to spatial planning - similarities and differences. Environmental Impact Assessment Review, Amsterdã, v. 26, n. 6, p. 586-599.

UMBUZEIRO, G. \& LORENZETTI, M. (2009) Fundamentos da gestão da qualidade das águas superficiais: resolução CONAMA 357/2005. Limeira: Unicamp.

VALENZUELA MONTES, L.M. \& MARATA'N RUIZ, A. (2008) Environmental indicators to evaluate spatial and water planning in the coast of Granada (Spain). Land Use Policy, Amsterdã, v. 25, n. 1, p. 95-105.

VILLAÇA, F. (2005) As ilusões do plano diretor. São Paulo: Edição do Autor. Disponível em: <http://www.flaviovillaca.arq.br/pdf/ilusao pd.pdf>. Acesso em: 10 maio 2009. 